\title{
Poverty reduction strategies via public-private partnerships:
}

\section{The role of e-government solutions in supporting supplier diversity programmes}

\author{
Ananda S. Jeeva \\ Lincoln C. Wood \\ School of Information Systems \\ Curtin Business School \\ Curtin University, Perth, Australia
}

\begin{abstract}
Government procurement practices influence large volumes of spending in communities and further procurement can be influenced through legislative efforts. Through these mechanisms government bodies carry significant influence on the way in which procurement spend occurs and they have the ability to influence the direction that the procurement may take. Carefully constructed parameters in public-private partnerships (PPP) can shift the focus of procurement activities towards engaging with the local businesses and communities. This represents an approach for government bodies to increase supplier diversity so that, in alignment with UN Millennium goals of poverty reduction, local suppliers can be provided with business opportunities and methods to reduce poverty. A two-focus approach is adopted; first, government drivers and policies are examined in the context of social engagement. Second, the roles and challenges faced by small firms in the local communities are highlighted. This demonstrates the way in which e-government procurement systems play a pivotal role in supporting local sourcing initiatives.
\end{abstract}

Key Words: Supplier Diversity, e-Procurement, Strategic Procurement, Poverty Reduction

\section{INTRODUCTION}

Poverty remains a wide-spread challenge in many developing countries. Since the 1960's there have been significant resources devoted to alleviating the challenge, yet both governments and non-government organizations (NGOs) experience variable successes in reducing poverty. This chapter outlines how government policy, coupled with effective use of public-private partnerships (PPPs) may be used to reduce poverty in local communities.

Sourcing of raw materials and other inputs for government-directed projects can be supplied and sourced form most developing or under-developed countries to produce final products or services for consumption. Such a programme is able to reduce trade deficits, improve monetary circulation in the local economies, and improve the socio-economic conditions of 
This is a copy of the 'post-print'; i.e., the final draft, post-refereeing. Published as:

Jeeva, A. S., \& Wood, L. C. (2012). Poverty reduction strategies via public-private partnerships: the role of e-government solutions in supporting supplier diversity programmes. In P. O. de Pablos, J. M. C. Lovelle, J. E. L. Gayo, \& R. Tennyson (Eds.), E-Procurement Management for Successful Electronic Government Systems (pp. 14-28). Hershey, PA: IGI Global. DOI: $10.4018 / 978-1-4666-2119-0 . c h 002$

families locally. Thus, strategic procurement using e-government systems are able to assist in poverty reduction through generating self-sustaining and renewing systems.

The United Nations Resolution of Millennium Declaration 55/2/III focuses on economic development and poverty reduction and outlines several approaches which our concept supplements. The UN Resolution promotes the role of local government and MNC in targeted assistance of economic growth in lower socio-economic areas in developing countries, frequently through developing, or instituting changes to, procurement policies and strategies.

Commitments were made to eradicate poverty (amongst other objectives) as part of the United Nations Millennium Development Goals (MDG). The intention was for sustained, broad-based, economic growth in impoverished regions to lift the welfare of residents and thus eliminate poverty. The MDGs also identified priority areas that needed to be addressed as part of this process, including alleviating hunger, policy development and implementation for food security, improving access to clean water, strengthening local capabilities, improving capability building, increasing vocational training, improving health, improving gender equality, youth unemployment, increasing trade, and improving development of domestic resources. These objectives are hardly new or novel, as aid organisations, governments, and NGOs have, for the last fifty years, been attempting to improve economic outcomes in all societies, frequently with limited success. Most of the world's population still survives below the 'poverty line'. In 1980 it was estimated that there were 1.9 billion people living below this poverty line. Over a 25-year period that has been little change: in 2005 it was estimated that there were still 1.4 billion people, or one quarter of the developing world, that lived below the international poverty line of \$1.25 US per day (Chen \& Ravallion, 2008).

Eight important goals were established during the 2000 UN Millennium Summit: ending hunger, achieving gender equality, improving the health of children, improving maternal health, combatting HIV/AIDs, creating global partnership, improving environmental sustainability, and providing universal education.

This chapter discusses poverty and procurement using e-government systems, focusing on the role of supplier diversity (SD) and procurement policies in meeting MDG objectives of reducing poverty. Poverty is examined in more detail, as well as the links between local governments, MNCs, aid organisations, and supplier diversity programmes implemented through procurement policies. Competitive advantages from SD programmes are outlined, along with the risks and challenges of implementation. As a solution, e-government systems and their role in promoting PPP relationships are discussed, demonstrating how SD programmes can be incorporated using e-government systems. Potential future challenges are discussed to provide future research directions.

\section{Supplier diversity and poverty}

First we define poverty and procurement to aid in following discussions.

\section{Poverty definition}

Poverty is frequently a slippery term, as the acceptable standard of living in different regions of the world can be perceived as being vastly different. Frequently definitions are based on income distributions within the society or the level of incomes achieved. Other national 
This is a copy of the 'post-print'; i.e., the final draft, post-refereeing. Published as:

Jeeva, A. S., \& Wood, L. C. (2012). Poverty reduction strategies via public-private partnerships: the role of e-government solutions in supporting supplier diversity programmes. In P. O. de Pablos, J. M. C. Lovelle, J. E. L. Gayo, \& R. Tennyson (Eds.), E-Procurement Management for Successful Electronic Government Systems (pp. 14-28). Hershey, PA: IGI Global. DOI: $10.4018 / 978-1-4666-2119-0 . c h 002$

governments will set local criteria for the level of poverty, based on a regional concept of poverty, which may be out of alignment with commonly accepted international standards.

However, a qualitative definition of poverty that has been widely accepted has been provided by the World Summit on Social Development in Copenhagen (1995), where absolute poverty was defined as "a condition characterised by severe deprivation of basic human needs, including food, safe drinking water, sanitation facilities, health, shelter, education and information as well as services." Six years later another key definition emerged from the United Nations Committee on Social, Economic and Cultural Rights, where in 2001 poverty was defined as "a human condition characterized by sustained or chronic deprivation of the resources, capabilities, choices, security and power necessary for the enjoyment of an adequate standard of living and other civil, cultural, economic, political and social rights” an expansion of the earlier definition to include a wider range of specific rights that poverty impinges upon.

\section{Procurement definition}

While procurement has always been present in all public and private endeavours throughout history, a clear definition has not always been forthcoming. A recent important definition of procurement is that it is "the function of purchasing inputs used in the firm's value chain, including raw materials, supplies and other consumables as well as machinery and equipment” (van Weele, 2005, p. 10). Other authors have noted that this is a restrictive and narrow definition, and have instead suggested that procurement is merely a wider term than purchasing, implying "the acquisition of goods or services in return for a payment of money, which may include borrowing or leasing” (Lysons \& Farrington, 2006, p. 6). More recently, there has been increasing focus on the role of procurement within organisations, taking a process-orientated perspective, highlighting the criticality of the function within successful contemporary organisations. The role therefore includes a range of activities and processes, such as "searching and qualifying suitable suppliers, negotiating terms, purchase orders, invoicing, shipping and remittance payment” (Laudon \& Traver, 2007, p. 689). With this perspective, procurement is not an isolated function within an organisation, and instead involves multiple inter-functional linkages within an organisation.

While many of these activities remain internal to an organisation, there are also important procurement activities that are externally-focused. Key amongst these is activities that emphasise a diverse range of suppliers, which may frequently include non-traditional, or regional, suppliers. Such suppliers may frequently have a lower level of professionalism and require additional effort through engagement to also provide coaching, than traditional procurement practices may indicate.

This chapter proposes that SD initiatives cannot be isolated or occur spontaneously within a procurement function. They must instead be nurtured through organisational vision and carefully designed strategies that encompass the entire organisation, and the links to the procurement department, to ensure success.

\section{Supplier Diversity}

The key element of supplier diversity (SD) programmes includes widening the supply base to include a greater breadth of non-traditional suppliers. The SD concept originated in the United States of America where the government began to pay attention to the role of small 
This is a copy of the 'post-print'; i.e., the final draft, post-refereeing. Published as:

Jeeva, A. S., \& Wood, L. C. (2012). Poverty reduction strategies via public-private partnerships: the role of e-government solutions in supporting supplier diversity programmes. In P. O. de Pablos, J. M. C. Lovelle, J. E. L. Gayo, \& R. Tennyson (Eds.), E-Procurement Management for Successful Electronic Government Systems (pp. 14-28). Hershey, PA: IGI Global. DOI: $10.4018 / 978-1-4666-2119-0 . c h 002$

businesses in the 1950s. The Small Business Administration (SBA) was initially established as a federal agency with the mandate to assist the initiation and growth of small businesses (www.sba.gov/aboutsba/). Soon after, during the 1960s, the burgeoning civil rights movement in the USA was generating greater attention and awareness of the relatively poor socio-economic status of minority groups within the USA (Shah \& Ram, 2006). These developments occurred in parallel before combining in 1972 when the National Minority Supplier Development Council was formed with the intention of developing and nurturing linkages between large corporates and (smaller) minority-owned business enterprises (MBEs), with the intention of improving the business opportunities for the smaller organisations. This was envisaged as occurring through changing the sourcing approaches used by corporates to include greater minority-owned business contributions. The concept of 'diversity' in SD therefore emphasises not a range of suppliers, or a widening supply base, but increasing 'diversity' through the inclusion of non-traditional, or non-corporate, suppliers.

Another recurring challenge, also acknowledged in the MDG, is gender inequality - still a significant social feature of many societies throughout the world. While a national population may consist of approximately $50 \%$ women, such numeric equality is rarely mirrored in other aspects of life. The exploitation, subjugation, and marginalisation of women in contemporary economic activities reduce the potential for a nation to fully develop their economic potential. As a result, only half of a nation's population is frequently engaged in reducing poverty through improving living standards.

In all of these cases, a minority group can be enfranchised through the development and deployment of SD programmes, which can be formulated to encourage engagement with these groups and foster entrepreneurship. This can align effectively with other, more established, programmes run by other agencies or NGOs that have been formed to break the established cycles of discrimination and oppression. Thus, SD models may include a range of suppliers from various groups that may include not only minority-owned businesses, but also suppliers including businesses run by other disadvantaged groups, such as women or war veterans. While many large corporates have yet to establish efforts in this area, there are sterling examples, such as Apple Inc., which established a SD programme in 1993. Other large firms, such as Caterpillar, have also implemented supplier diversity programmes and found that not only are sourcing costs lowered, quality can be enhanced, providing additional competitive advantage, but the process may require careful planning (Min, 2009). This trend towards SD initiatives may continue as other larger corporates begin to acknowledge economic support for communities can translate into improved purchasing power, and thus greater demand, creating new, localised, business opportunities for the firms (Jeeva, 2011).

\section{Government and poverty in the community}

Local Governments are powerful change agents within their regional communities (Edmondson, Suh, \& Munchus, 2008) through changing the intentions, societal behaviours, and operations within the communities of the society. Governmental organisations have the capability to generate increasingly large opportunities for minority groups throughout the region, through encouraging ownership, providing education, and improving linkages to multinational corporations (MNC) and global aid organisations. 
This is a copy of the 'post-print'; i.e., the final draft, post-refereeing. Published as:

Jeeva, A. S., \& Wood, L. C. (2012). Poverty reduction strategies via public-private partnerships: the role of e-government solutions in supporting supplier diversity programmes. In P. O. de Pablos, J. M. C. Lovelle, J. E. L. Gayo, \& R. Tennyson (Eds.), E-Procurement Management for Successful Electronic Government Systems (pp. 14-28). Hershey, PA: IGI Global. DOI: $10.4018 / 978-1-4666-2119-0 . c h 002$

Relationships between globalised aid organisations and Global organisations require local partnerships to create effective change and thus the global aid organisations contract and fund their local organisations so that they can jointly create successful projects. Success and longterm effectiveness of projects for the organisations rely on these local collaborators. This can be particularly important as global staff rarely have adequate interaction with recipients of aid locally (Satterthwaite, 2001). The two parties, therefore, lack suitable connections and the challenge of sustained project success.

Local governments make ideal partners as they are embedded within their communities and have a commitment to local improvements and serving their citizens. Through their mechanisms local government officers should spearhead change and ensure that strategies implemented within their communities are sustainable. This is part of their responsibility to encourage economic development within the region. With a significant input of resources, local governments have the ability to create significant change through their sourcing, where a local focus can improve engagement with communities and strengthen the local economy while also improving regional employment.

Both federal and local government bodies may need appropriate legislation in place to encourage or nurture organisations - including government bodies and their agencies - to modify procurement policies to support the local communities. The steps can be enhanced through the compilation of guidelines to promote 'buying locally produced products and services first'. The approach can be spearheaded by local government agencies, providing impetus to other organisations to replicate the concept, while providing immediate equitable results for their communities.

When the approach is first implemented there will be a shortage of suppliers that meet the requirements and are capable of sustained effective supply. The shortage will force the creation of many new suppliers to meet the procurement objectives outlined by the procuring agency and this creation of new suppliers provides the opportunity for minority groups to become involved. The opportunity provides the potential for significant benefit for the community and the greater economic structure in such a way that the poverty can be reduced in the community through the provision of greater employment.

The role of procurement is important in contemporary environments and so this approach must be carefully considered and executed. Strategic procurement strategies have been recognised as essential in the age of global competitiveness (Baier, Hartmann, \& Moser, 2008), yet most procurement research and the extant literature tends to promote the concept that economic gain, through cost reductions, provides suitable impetus for new policies. The contention of this chapter is sharply different: carefully designed strategic procurement policies can promote local sourcing, expanding local customer bases, and increasing market opportunities locally. Thus, sourcing locally provides support to the communities, the members of which consume services and outputs from government organisations. Such an approach presents a cyclic vision of a local, community-focused, supply system, where suppliers of materials into a government agency may be consumers of products or services which their materials contributed to. It is a like a close economic system, such as found in small, isolated, communities, where all production is consumed within the community. 
This is a copy of the 'post-print'; i.e., the final draft, post-refereeing. Published as:

Jeeva, A. S., \& Wood, L. C. (2012). Poverty reduction strategies via public-private partnerships: the role of e-government solutions in supporting supplier diversity programmes. In P. O. de Pablos, J. M. C. Lovelle, J. E. L. Gayo, \& R. Tennyson (Eds.), E-Procurement Management for Successful Electronic Government Systems (pp. 14-28). Hershey, PA: IGI Global. DOI: $10.4018 / 978-1-4666-2119-0 . c h 002$

Such a system is unlikely to occur spontaneously and may need to be encouraged through the implementation of new SD programmes and related procurement policies, which may rely on suitable support by government legislation or requirements. PPPs can be influenced by governments, which may provide governments with a method to influence significant procurement that they do not directly engage in. SD programmes can therefore be implemented in such a way to benefit local users of services. Additional efforts may be required to support SD programmes through the implementation of infrastructure improvements that may help smaller, newer, suppliers to gain the capabilities to engage with businesses, through training, education, and e-government systems.

\section{Designing policies to influence supplier diversity through procurement}

The rational and requirement for SD programmes is heterogeneous globally. In some countries, such as the USA, there are adequate incentives for organisations to introduce these programmes, while in others, such as Australia, the minority population is smaller and the programmes need additional support (Blake, 2007). Such a programme, however, does have significant advantages for a country such as Australia, allowing indigenous Australians the opportunity to break free from the welfare cycle (Jeeva, 2011). Such differences in business climates and society mean that incentives may be required to help encourage the introduction of SD programmes, such as the opportunity for organisations to engage with their local community and provide development opportunities. Such an approach creates jobs and increases local capabilities, yet the challenges may require significant leadership capabilities and may require support from governments through financial incentives, legislation, or ground-breaking practices that may be emulated by other organisations.

Many organisations will also find new challenges in SD programmes as they change the focus from rationalisation of the supply base, running counter to conventional procurement wisdom. Additionally, the concept requires greater thought, planning, and creativity in the management of procurement and purchasing.

\section{Outcome and motivation for SD}

The overall outcomes and rationale for moving towards SD programmes is important to understand, as the concept can provide significant competitive advantage.

Effective operations are often predicated by effective supplier relationships and strong supply networks, providing a solid foundation for supply chain management and sustained competitiveness. Yet, many organisations find that supplier development and relationship management can be challenging and time-consuming in traditional business environments. This is frequently due to a lack of trust between parties and power imbalances in the supply chain. Contrastingly, minority or disadvantaged groups are more likely to provide a motivated partner for a buying organisation, a partner that is keen to cooperate and comply with set requirements, whether they are quality standards, lead times, or other critical factors. In this way, a more cooperative spirit in the supply chain may be achieved through engaging SD programmes.

There are three key influences of SD programmes: ethical, economic opportunities, and stakeholder expectations. 
This is a copy of the 'post-print'; i.e., the final draft, post-refereeing. Published as:

Jeeva, A. S., \& Wood, L. C. (2012). Poverty reduction strategies via public-private partnerships: the role of e-government solutions in supporting supplier diversity programmes. In P. O. de Pablos, J. M. C. Lovelle, J. E. L. Gayo, \& R. Tennyson (Eds.), E-Procurement Management for Successful Electronic Government Systems (pp. 14-28). Hershey, PA: IGI Global. DOI: $10.4018 / 978-1-4666-2119-0 . c h 002$

Particularly in the UK, the concept of corporate social responsibility (CSR) has been heavily influenced through the promotion of 'think small first' campaign, which has promoted the inclusion and engagement with small businesses including MBEs. Overwhelmingly, ethical concerns have been the key driving force behind the adoption of most CSR strategies, including SD programmes. While the origins in the UK for CSR programmes may have been swayed by social issues, this is changing as more firms realise that enhancing their reputation is critical as this has long been recognised as being linked to strategic advantage (Bharadwaj, Varadarajan, \& Fahy, 1993). Public relations work can enhance the public perception of these strategies, increasing business legitimacy (Suchman, 1995) in the public sector, providing for competitive advantages, and recognising that the suppliers also represent a market and potential workforce.

Localised economic impacts and new economic opportunities also influence CSR. With a domino effect, MBEs that secure contracts with large buying organisations are able to influence their local communities and other businesses. They may also invest resources into combating economic inequality where other organisations have failed. Overall, this can lead to societal groups where there is reduced crime and improved quality of life, while the rising wealth can lead to increased demand for the output from the original buying organisation. SD programmes can therefore provide further competitive advantage.

The expectations and legitimation secured in the local communities can be an important motivating factor in the establishment of CSR programmes. Engagement with a range of stakeholders, such as potential customers, lobby groups, new business partners, employees and other agencies can be seen as a positive reflection of SD on the community. Here, SD is a mechanism to enhance stakeholder satisfaction with the buying organisations, thereby providing competitive advantage to the organisation (Shah \& Ram, 2006)

\section{Competitive advantage through SD}

Despite the apparent additional complexity that should arise from working with a supply base of diverse suppliers, Kerr (2006) asserts that firms successfully implementing SD programmes are more successful due to the increase in minority business. Recent research by the Hackett Group also finds significant benefits, stating that organisation with diverse suppliers tended to outperform average firms, with $133 \%$ greater return on costs of procurement operations. The indication is that rapidly the additional costs relating to increased procurement complexity may be balanced by improved revenue. Firms sourcing from effective MBEs, by sourcing competitively, encourage growth in the sector and, thereby, improve their reputation and gain new markets and customers. A multi-sourcing strategy using SD policies may rapidly become more cost-effective than single-sourcing policies - which should provide significant encouragement for organisations seeking to use this approach.

While rapid cost benefits are possible, other procurement-related benefits can also be realised with a SD-based multi-sourcing strategy. Working with a wider range of organisations also exposes a buying organisation to greater possibilities of being exposed to innovative solutions to their own problems (Carter, Auskalnis, \& Ketchum, 1999). Exposure to new ideas and approaches may lead to adoption of cutting edge concepts in the buying organisation to provide significant strategic advantage. 
This is a copy of the 'post-print'; i.e., the final draft, post-refereeing. Published as:

Jeeva, A. S., \& Wood, L. C. (2012). Poverty reduction strategies via public-private partnerships: the role of e-government solutions in supporting supplier diversity programmes. In P. O. de Pablos, J. M. C. Lovelle, J. E. L. Gayo, \& R. Tennyson (Eds.), E-Procurement Management for Successful Electronic Government Systems (pp. 14-28). Hershey, PA: IGI Global. DOI: $10.4018 / 978-1-4666-2119-0 . c h 002$

Benefits may accrue in the future, providing further compelling reasons to adopt SD programmes. As an example, in the USA it has been projected that at current rates of demographic change, by 2045 minority groups may represent $46 \%$ of the total US population (Worthington, Ram, Boyal, \& Shah, 2008) - representing a significant market share in the world's largest economy. Early engagement with these communities may allow an organisation to establish strong links with groups that may prove to be powerful markets in the near future. Having a strong first-mover advantage may also enable sustainable competitive advantage and deter new entrants. Furthermore, the use of business intelligence gained from the SD implementation can also provide additional insights and understanding of new market segments, helping marketers to derive the needs of a diverse new customer base (Slater, Weigand, \& Zwirlein, 2008).

The ability to react to volatile markets can provide significant benefits to firms (Christopher, Lowson, \& Peck, 2004) and organisational agility may be enhanced through SD programmes. Small MBEs may have increased flexibility to change to economic challenges, or even the requirements of a buying organisation, largely due to their smaller organisation structure (Golder, 2004). Smaller size firms are also more likely to be owner-operated, providing greater likelihood of being dynamic and responsive to new requirements. This flexibility can also translate into being able to provide more customised solutions for clients than larger, single, suppliers may be able to achieve (Ram \& Smallbone, 2003). Procurement can, therefore, provide support for agility throughout the organisation by working with these more agile suppliers.

Many developing regions may benefit and are ripe for the innovation of SD. As an example, in regional Thailand regions, which are agrarian-based economies, many farmers have eschewed relying solely on traditional farm activities for various reason and have created a portfolio of economic activities (Rigg \& Nattapoolwat, 2001). A core farming activity in the region is rice cultivation. Many fathers are now involved part-time manufacture of artificial flowers, an activity that provides similar incomes to their main employment, while providing more direct compensation while being more fun and less physically demanding than farming. Other regions have also seen similar changes, particularly involving women as an important demographic group. Many aid organisations have attempted to raise the profile of women as this group is rapidly becoming better educated, increasing their buying power and decisionmaking capabilities within their communities.

\section{Strategic and supplier diversity risks and challenges}

The implementation of SD programmes is not without challenge or difficulty, particularly due to the relatively poor management and technological capabilities of the new potential suppliers, and the difficulty of finding qualified suppliers.

Previous studies have indicated that it is critical to proactively address the capabilities of potential MBE suppliers (Shah \& Ram, 2006). While some forms of engagement may be virtual, relying on technology, in developing countries it is more critical for information to be provided on a face-to-face basis. Typical engagement with new suppliers may include business fairs, presentations, 'meet the buyer' sessions, or trade shows; other outreach activities may raise the general awareness of the community. 
This is a copy of the 'post-print'; i.e., the final draft, post-refereeing. Published as:

Jeeva, A. S., \& Wood, L. C. (2012). Poverty reduction strategies via public-private partnerships: the role of e-government solutions in supporting supplier diversity programmes. In P. O. de Pablos, J. M. C. Lovelle, J. E. L. Gayo, \& R. Tennyson (Eds.), E-Procurement Management for Successful Electronic Government Systems (pp. 14-28). Hershey, PA: IGI Global. DOI: $10.4018 / 978-1-4666-2119-0 . c h 002$

Many MBEs will not be technologically savvy and may lack the appropriate technology or equipment to engage with a large buying organisation as a large supplier would. This requires adjustment on the part of the buying organisation, which must be more flexible and provide appropriate inter-organisational interfaces when dealing with these suppliers. Long-term relationships with key suppliers and a mentoring programme may need to be established, as the larger buyers may need to provide a nurturing environment (Bates, 2001). Such a programme can also help overcome a scarcity of suppliers or a lack of specific capabilities.

While cost is always a consideration during procurement, other important factors include stability of supply, quality, and lead-times (Lysons \& Farrington, 2006). These additional requirements must be clearly communicated with MBE suppliers, as disruptions in supply, quality problems, or long lead times may negatively impact on the ability to supply a buying organisation's own customers. Initial articulation of requirements and on-going management of these factors is critical in the SD programme and will require more than just a champion; practices must be codified and recorded to enable effective monitoring.

Senior management support and commitment to the programme is critical for success. SD programmes must be supported by all staff in the buying organisation (Whitfield \& Landeros, 2006). Several important internal requirements must be considered, particularly the initial costs of resourcing required to undertake an effective SD programme. Work must be undertaken to generate a potential pool of adequate suppliers while guidelines and requirements must be carefully codified to align with corporate requirements. Policies relating to procurement must also incorporate elements that are deemed important in the vision and mission statements as marketed to the public. Staff allocations should be undertaken with the consideration that not all members will be equally committed to SD programmes; appropriate staff should be further empowered and enabled to understand their KPIs. Finally, external factors should be evaluated, particularly the ability for the organisation to undertake public awareness campaigns, highlighting their CSR objectives and their community relationships.

Perhaps a key challenge to implementation of SD programmes is the drive for shareholder value and the concomitant move towards rationalisation of the supply base, which appear, initially, to provide significant roadblocks. Contemporary procurement practices favour the consolidation and optimisation of the supplier base during supplier rationalisation programmes (Lysons \& Farrington, 2006). This change in the supply base is an attempt to achieve competitive advantage with fewer relationships that are more carefully managed and are longer-term (Pearson, Fawcett, \& Cooper, 1993). Similarly, Adobor and McMullen (2007) have suggested that modern production approaches, such as Just in Time (JIT), have resulted in a greater reliance on fewer preferred suppliers, representing a natural contraction of the supply base. Initially, SD may seem to run counter to these concepts.

Locating qualified suppliers that have the requisite capabilities and available capacity is perceived by larger organisations as a significant barrier to SD adoption. Such suppliers do tend to cluster infrequently in particular industries and may lack skills, capital, and technology. Moreover, small and medium enterprises (SMEs) may also represent their capabilities (either intentionally or otherwise) to win corporate contracts (Dollinger, Enz, \& Daily, 1991). Krause et al. (1999) confirm that these problems of access to capital, the conflict between supplier rationalisation and SD adoption, and a lack of qualified staff in 
This is a copy of the 'post-print'; i.e., the final draft, post-refereeing. Published as:

Jeeva, A. S., \& Wood, L. C. (2012). Poverty reduction strategies via public-private partnerships: the role of e-government solutions in supporting supplier diversity programmes. In P. O. de Pablos, J. M. C. Lovelle, J. E. L. Gayo, \& R. Tennyson (Eds.), E-Procurement Management for Successful Electronic Government Systems (pp. 14-28). Hershey, PA: IGI Global. DOI: $10.4018 / 978-1-4666-2119-0 . c h 002$

potential suppliers negatively impacts the ability of the diverse suppliers to secure adequate business.

One method to overcome the challenge of rationalisation and qualification of suppliers is the use of supply cooperatives. MBEs can form cooperatives to increase their own purchasing power, negotiation power with buying organisations, and creating a consolidated and pseudoconsolidated supply base for corporations. The cooperative structure can act as a 'buffer' and improve supplier relationship management, and ensure that appropriately qualified suppliers are selected and used for work, while providing buying organisations with confidence in the stability and long-term prospects of suppliers. The cooperative can undertake some of the work that may otherwise be undertaken by the buying organisation.

Alignment of SD objectives with corporate objectives is also important. Existing culture and strategies will have influenced the current procurement and supply management practices. Separate and novel objectives relating to CSR, incorporating elements of the SD programme, will need to be introduced separately, rather than trying to align the programme with existing strategies and extant culture. This is particularly true as many extant approaches will promote a focus on cost-reduction and efficiency through supply rationalisation (Baily, Farmer, Jessop, \& Jones, 2008). While SD may initially be believed to increase risks and complications in terms of SRM, long-term benefits in CSR should outweigh these considerations and be moderated through the implementation of supply-side solutions.

\section{Possible supply-side solutions}

Many of the challenges that have been discussed may be mitigated by diverse suppliers or MBEs forming a business cooperative. This will present a single, unified façade, to the buying organisation and it is recognised as being able to prevent the incidence of power imbalances in the relationship (Kelliher, 2007).

Globally there are several cottage industries where production occurs in a home-based environment as opposed to in a factory. The items tend to be unique or created on a smallscale and are not mass-produced. The output may, however, be components for use in largerscale production. However, the volumes required for a manufacturer to compete in a traditional retail supply chain will likely outstrip the capacity of a single supplier. In addition there may be other disadvantages that cottage industries face as they compete with factorybased production, such as the fact that they are not part of established supplier networks and require additional commitment to include them in the supply base.

The presence of a supplier cooperative alone may not, however, be adequate. Changes inside of the buying organisation must also occur. The commitment to SD practices must be cultivated carefully and embodied within the emerging culture to ensure that all behaviours are appropriate. There is required to be deep commitment which may be improved through demonstration of the value of diversity to success, the provision of clear targets and appropriate metrics, emphasis on fairness and a clear rationale, crafting appropriate SD strategies aligned with senior executive expectations, the identification of diverse suppliers, and the implementation of methods to avoid conflicts between the parties (Slater, et al., 2008).

\section{E-Government solutions in PPP arrangements}


This is a copy of the 'post-print'; i.e., the final draft, post-refereeing. Published as:

Jeeva, A. S., \& Wood, L. C. (2012). Poverty reduction strategies via public-private partnerships: the role of e-government solutions in supporting supplier diversity programmes. In P. O. de Pablos, J. M. C. Lovelle, J. E. L. Gayo, \& R. Tennyson (Eds.), E-Procurement Management for Successful Electronic Government Systems (pp. 14-28). Hershey, PA: IGI Global. DOI: $10.4018 / 978-1-4666-2119-0 . c h 002$

A more modern approach to SD, able to overcome many of the challenges, is the use of egovernment solutions. In a nutshell e-government means "governance through the use of information and communication technology (ICT)” (Sharma \& Loh, 2009, p. 204), providing the ability for efficient and transparent interaction between a government body (or agency) and other stakeholders in society, using ICT. These systems allow the bundling and simplification of business processes to provide "simplified procedures and shorter lead times, making the system more approachable for smaller, less well-resourced, enterprises" (Panayiotou, Gayialis, \& Tatsiopoulos, 2004, p. 100); in procurement such a system may encompass tenders, workflow, electronic marketplaces, electronic catalogues, and exchange and auctions. The use of ICT to improve government may have connotations of a standardised government approach, removing the alibility or opportunity for flexibility through improved autonomy. Yet, e-government has been promoted strongly as a key platform for government reform and appears as a natural match to the improved engagement with community as "digital government must reposition itself to become an engaged and constructive partner in shaping the new governance patterns" (Allen, Juillet, Paquet, \& Roy, 2001, p. 103), presenting a natural alignment of constructs and philosophies.

Policies relating to public procurement can be utilised as a tool to bring about desired changes (Rolfstam, 2009). They can provide a method for local and federal governments to make small investments in infrastructure and finances (like co-operatives) to assist marginalised groups to start-up businesses, or create incubators to develop specialised cottage industries, acting in an incubatory role. Not only can financial investments be made in a community, but there can be improved exchange of knowledge and information, inciting greater technological development in the wider community (Phillips, Knight, Caldwell, \& Warrington, 2007).

The potential benefits of e-government to developing regions are substantial; however there are significant shortfalls in the funding and capabilities or skills available in the public sectors that may make the concept impractical. One method that may help address this is the PPP, which is "an agreement between government and businesses or NGOs for the provision of services by sharing of risks and rewards of the venture” (Sharma \& Loh, 2009, p. 205).

Through the use of the PPP model, suitable amounts of talent and funding may be utilised in e-government projects. The model seeks to overcome the barrier of 'lack' in the government, providing greater speed, efficiency, and service in government provision of services. Partners may be suitable organisations from industry or other groups within society such as nonprofits (Lawther, 2003), which leverage their capabilities so that they can complement the government agency strengths. The approach is critical as it has proven to be a "viable business model for e-Government implementation, to impart economic sustainability and provide necessary soft-skills [. . .] where there is a lack of critical resources such as finances and technical skills” (Sharma \& Loh, 2009, p. 210).

\section{PPP use with governments}

PPPs may be advantageous where there is a higher level of complexity, as mechanisms are instituted to ensure that participants interact as equals, changing the relationships. The model is particularly useful in situations where there is a high level of risk, trust, commitment, coordination, complexity or uncertainty, and cost-sharing that is required (Lawther, 2003, p. 208). The implementation needs to be carefully considered, particularly concerning risk 
This is a copy of the 'post-print'; i.e., the final draft, post-refereeing. Published as:

Jeeva, A. S., \& Wood, L. C. (2012). Poverty reduction strategies via public-private partnerships: the role of e-government solutions in supporting supplier diversity programmes. In P. O. de Pablos, J. M. C. Lovelle, J. E. L. Gayo, \& R. Tennyson (Eds.), E-Procurement Management for Successful Electronic Government Systems (pp. 14-28). Hershey, PA: IGI Global. DOI: $10.4018 / 978-1-4666-2119-0 . c h 002$

allocation and conversations between parties before the contract is awarded (Li, Akintoye, Edwards, \& Hardcastle, 2005a).

Three key success factors for the implementation of PPPs include the presence of a strong private consortium, appropriate risk allocation models between the parties, and the availability of financial support and financial markets (Li, Akintoye, Edwards, \& Hardcastle, 2005b) p. 496. It has also been suggested that there are important underlying legal elements, such as legal values, democratic participation, particularly as the modern governments act to facilitate and support the provision of services that are being more frequently supplied by other parties using PPP arrangements (Lienhard, 2006, p. 558). Strong internal integration is important to maintain cost-effectiveness, while integration with suppliers will vastly improve the supply reliability (Lee, Kwon, \& Severance, 2007).

Through the ability to open a portal to governments, government agencies, and partners, egovernment systems and the incorporation of e-procurement systems within PPPs provide significant opportunities - all of which can be influenced through the introduction of appropriate procurement policy. Their use offsets some of the technological and managerial challenges that diverse suppliers face, helping to reduce the challenges of implementing SD programmes in PPPs, providing that suitable cultural and managerial changes can be made internally.

\section{Conclusion}

Supplier diversity is business process that seeks to provide suppliers equal access to supply management opportunities and it may be enhanced through appropriate procurement policies that influence e-government and PPP structures. There are multiple examples that provide strong business cases for the adoption of SD initiatives, particularly as minority groups represent significant future growth markets in many societies globally, both in developed and developing nations. SD programmes can also offer implementing organisations certain strategic benefits including:

- Increased returns on procurement activities

- Improved stakeholder satisfaction

- Greater engagement in the local communities

- Economic opportunities in local communities through a domino effect

- Improved corporate image through application of CSR models

- Improved agility, flexibility, and resilience to change in the buying organisation.

While SD initiatives were taken to support minority groups and other disadvantaged society groups in developed countries, we have demonstrated that the concept can be applied in other regions to improve standards of living. This chapter has asserted that procurement policies, particularly those of governmental agencies, represent a key lever in the battle with poverty particularly where PPPs are concerned.

A strategy for buying companies wishing to implement a SD programme must have multiple facets. Firstly Government bodies and MNCs must establish CSR policies. Second, Local governments should actively identify communities or disadvantaged groups that may benefit from SD involvement. Third, CSR policies should be translated into appropriate and aligned procurement policies that promote SD programmes and management. Fourth, local 
This is a copy of the 'post-print'; i.e., the final draft, post-refereeing. Published as:

Jeeva, A. S., \& Wood, L. C. (2012). Poverty reduction strategies via public-private partnerships: the role of e-government solutions in supporting supplier diversity programmes. In P. O. de Pablos, J. M. C. Lovelle, J. E. L. Gayo, \& R. Tennyson (Eds.), E-Procurement Management for Successful Electronic Government Systems (pp. 14-28). Hershey, PA: IGI Global. DOI: $10.4018 / 978-1-4666-2119-0 . c h 002$

governments must support the development of capacity and capability within communities, which may be aided by the implementation of e-government and e-procurement systems within PPP programmes.

Such ventures may also be aided through supply-side initiatives, such as the formation of cooperatives. Such cooperatives may also require government support, particularly in developing improved infrastructure and management capabilities.

E-government and e-procurement programmes can support the development of effective PPPs that can be influenced through government policy to source from the local community. This can provide an important boost to local communities and economies, and may be supplemented with the development of supply-side cooperatives, enabling effective engagement with diverse suppliers.

We suggest that that:

- Corporate Social Responsibility should be aligned with organisation mission statements and objectives

- Organisation performance may be improved through SD initiatives

- Procurement policies, and CSR initiatives such as SD, can provide advantage to organisations

- Careful evaluation of diverse suppliers is required and support and a long-term relationship may be required to enable effective supplier development

- Procurement policies of government agencies can influence e-government systems and PPPs to encourage development of SD programmes.

Governments can influence their own procurement, and that of other organisations using PPPs, to encourage greater engagement with local communities using SD programmes. These may allow governments to transform local communities and may provide a method for governments to move towards objectives established in the UN Millennium Declaration Goals.

\section{References}

Adobor, H., \& McMullen, R. (2007). Supplier diversity and supply chain management: A strategic approach. Business Horizons, 50(3), 219-229.

Allen, B. A., Juillet, L., Paquet, G., \& Roy, J. (2001). E-Governance \& government on-line in Canada: Partnerships, people \& prospects. Government Information Quarterly, 18(2), 93-104.

Baier, C., Hartmann, E., \& Moser, R. (2008). Strategic alignment and purchasing efficacy: An exploratory analysis of their impact on financial performance. Journal of Supply Chain Management, 44(4), 36-52.

Baily, P., Farmer, D., Jessop, D., \& Jones, D. (2008). Procurement Principles and Management (10th ed.). London: Prentice Hall.

Bates, T. (2001). Minority business access to mainstream markets. Journal of Urban Affairs, 23(1), 41-56.

Bharadwaj, S. G., Varadarajan, P. R., \& Fahy, J. (1993). Sustainable competitive advantage in service industries: A conceptual model and research propositions. The Journal of Marketing, 57(4), 83-99.

Blake, J. (2007). Caring for the bottom line. [Article]. Human Resource Planning, 30(1), 36-44. 
This is a copy of the 'post-print'; i.e., the final draft, post-refereeing. Published as:

Jeeva, A. S., \& Wood, L. C. (2012). Poverty reduction strategies via public-private partnerships: the role of e-government solutions in supporting supplier diversity programmes. In P. O. de Pablos, J. M. C. Lovelle, J. E. L. Gayo, \& R. Tennyson (Eds.), E-Procurement Management for Successful Electronic Government Systems (pp. 14-28). Hershey, PA: IGI Global. DOI: $10.4018 / 978-1-4666-2119-0 . c h 002$

Carter, C. R., Auskalnis, R. J., \& Ketchum, C. L. (1999). Purchasing from minority business enterprises: Key success factors. Journal of Supply Chain Management, 35(1), $28-32$.

Chen, S., \& Ravallion, M. (2008). The developing world is poorer than we thought, but no less successful in the fight against poverty. The World Bank Development Research Group. Retrieved from http://elibrary.worldbank.org/docserver/download/4703.pdf?expires=1328136769\&id=id\&ac cname=guest\&checksum=13842B7AFFC09192E20FCFBA7D547269

Christopher, M., Lowson, R., \& Peck, H. (2004). Creating agile supply chains in the fashion industry. International Journal of Retail \& Distribution Management, 32(8/9), 367-376.

Dollinger, M. J., Enz, C. A., \& Daily, C. M. (1991). Purchasing from minority small businesses. International Journal of Purchasing and Materials Management, 27(2), 9-14.

Edmondson, V. C., Suh, W. S., \& Munchus, G. (2008). Exceeding government-mandated social programs: Minority supplier development programs. Management Research News, 31(2), $111-124$

Golder, A. (2004). Buyers prefer web to find suppliers. Supply Management, 9(10), 8-10.

Jeeva, A. (2011). Poverty reduction strategies via procurement policies. Paper presented at the The 20th annual IPSERA conference (International Purchasing and Supply Education and Research Association), Maastricht, The Netherlands: Maastricht University.

Kelliher, F. (2007). Small firm cooperative constructs: Addressing industry power relationships. Journal of Small Business and Enterprise Development, 14(3), 501-513.

Kerr, J. (2006). The changing complexion of supplier diversity. Supply Chain Management Review, 10(2), 38-45.

Krause, D. R., Ragatz, G. L., \& Hughley, S. (1999). Supplier development from the minority supplier's perspective. Journal of Supply Chain Management, 35(4), 33-41.

Laudon, K. C., \& Traver, C. G. (2007). E-Commerce: Business, technology, society (3rd ed.). Upper Saddle River, N.J.: Prentice Hall.

Lawther, W. C. (2003). Contracting for the 21st century: A partnership model. In M. A. Abramson \& R. S. Harris III (Eds.), The Procurement Revolution (pp. 167-216). Lanham, MD: Rowan and Littlefield.

Lee, C. W., Kwon, I.-W. G., \& Severance, D. (2007). Relationship between supply chain performance and degree of linkage among supplier, internal integration, and customer. Supply Chain Management, 12(6), 444-452.

Li, B., Akintoye, A., Edwards, P. J., \& Hardcastle, C. (2005a). The allocation of risk in PPP/PFI construction projects in the UK. International Journal of Project Management, 23(1), 25-35.

Li, B., Akintoye, A., Edwards, P. J., \& Hardcastle, C. (2005b). Critical success factors for PPP/PFI projects in the UK construction industry. Construction Management and Economics, 23(5), 459-471.

Lienhard, A. (2006). Public private partnerships (PPPs) in Switzerland: Experiences-riskspotentials. International Review of Administrative Sciences, 72(4), 547-563.

Lysons, K., \& Farrington, B. (2006). Purchasing and Supply Chain Management (7th ed.). Essex, UK: Pearson Education.

Min, H. (2009). The best-practice supplier diversity program at Caterpillar. Supply Chain Management, 14(3), 167-170.

Panayiotou, N. A., Gayialis, S. P., \& Tatsiopoulos, I. P. (2004). An e-procurement system for governmental purchasing. International Journal of Production Economics, 90(1), 79-102.

Pearson, J. N., Fawcett, S. E., \& Cooper, A. (1993). Challenges and approaches to purchasing from minority-owned firms: A longitudinal examination. [Article]. Entrepreneurship: Theory \& Practice, 18(2), 71-88.

Phillips, W., Knight, L., Caldwell, N., \& Warrington, J. (2007). Policy through procurement - The introduction of digital signal process (DSP) hearing aids into the English NHS. Health Policy, 80(1), 77-85. 
This is a copy of the 'post-print'; i.e., the final draft, post-refereeing. Published as:

Jeeva, A. S., \& Wood, L. C. (2012). Poverty reduction strategies via public-private partnerships: the role of e-government solutions in supporting supplier diversity programmes. In P. O. de Pablos, J. M. C. Lovelle, J. E. L. Gayo, \& R. Tennyson (Eds.), E-Procurement Management for Successful Electronic Government Systems (pp. 14-28). Hershey, PA: IGI Global. DOI: $10.4018 / 978-1-4666-2119-0 . \operatorname{ch} 002$

Ram, M., \& Smallbone, D. (2003). Supplier diversity initiatives and the diversification of ethnic minority businesses in the UK. [Article]. Policy Studies, 24(4), 187-204.

Rigg, J., \& Nattapoolwat, S. (2001). Embracing the global in Thailand: Activism and pragmatism in an era of deagrarianization. World Development, 29(6), 945-960.

Rolfstam, M. (2009). Public procurement as an innovation policy tool: The role of institutions. Science and Public Policy, 36(5), 349-360.

Satterthwaite, D. (2001). Reducing urban poverty: Constraints on the effectiveness of aid agencies and development banks and some suggestions for change. Environment and Urbanization, 13(1), 137-157.

Shah, M., \& Ram, M. (2006). Supplier diversity and minority business enterprise development: Case study experience of three US multinationals. Supply Chain Management, 11(1), 75-81.

Sharma, A., \& Loh, P. (2009). Emerging trends in sourcing of business services. Business Process Management Journal, 15(2), 149-165.

Slater, S. F., Weigand, R. A., \& Zwirlein, T. J. (2008). The business case for commitment to diversity. Business Horizons, 51(3), 201-209.

Suchman, M. C. (1995). Managing legitimacy: Strategic and institutional approaches. The Academy of Management Review, 20(3), 571-610.

van Weele, A. J. (2005). Purchasing \& supply chain management: Analysis, strategy, planning and practice (4th ed.). Australia: Thomson

Whitfield, G., \& Landeros, R. (2006). Supplier diversity effectiveness: Does organizational culture really matter? Journal of Supply Chain Management, 42(4), 16-28.

Worthington, I., Ram, M., Boyal, H., \& Shah, M. (2008). Researching the drivers of socially responsible purchasing: A cross-national study of supplier diversity initiatives. [Article]. Journal of Business Ethics, 79(3), 319-331. 